\section{Correspondence to 'Associations of regular glucosamine use with all-cause and cause- specific mortality: a large prospective cohort study' by Li et al}

With great interest, we have read the recent article from Li $e t$ $a l$, which addressed the link between regular glucosamine use and all-cause and cause-specific mortality in a large prospective cohort from the UK biobank. ${ }^{1}$ These authors are dedicated to providing valuable insights and comprehensive analysis for HRs associated with glucosamine use, 0.85 (95\% CI 0.82 to 0.89 ) of all-cause mortality, 0.82 ( $95 \%$ CI 0.74 to 0.90 ) of cardiovascular disease mortality, 0.94 (95\% CI 0.88 to 0.99 ) of cancer mortality, 0.73 (95\% CI 0.66 to 0.81 ) of respiratory mortality and 0.74 (95\% CI 0.62 to 0.90$)$ of digestive mortality. However, some methodological issues of these findings must be considered.

First, the definition of regular glucosamine use should be described more detailed. It is important to present factors such as dosage, frequency and treatment adherence, which may make confounded dose-response effects. Optimal dosage, which builds a basis for exhibiting the effectiveness of drugs at various levels of dosage, can also provide a better approach to assess the protective effect of glucosamine. For example, Simon et al used high/low dose, date, number of pills, defined daily dose, cumulative dose and duration to evaluate the association of aspirin with hepatocellular carcinoma and liver-related mortality. ${ }^{2}$ Second, we observed that some residual confounders would have to be strongly related to HRs of mortality, like stress, air pollution and nutrition status. To the best of our knowledge, negative controls can be a method of detecting uncontrolled confounding. They are irrelevant factors designed for finding spurious causal inference and generally expected to give a result of no association after an analysis. When it turns out different, the main association may be biased by the same procedures which brought about the failure of negative-control experiment. ${ }^{3-5}$ Therefore, we recommend negative-control outcome (ie, glucosamine and accidental trauma) and negative-control exposure (ie, dental care participation and mortality) as two kinds of negative control design to improve causal inference of this study. Third, the habits of glucosamine use are likely to have inference with HRs of mortality. Glucosamine users often take glucosamine as a nutritional supplement. They regard it as one of the methods to keep a healthy lifestyle, thus be more physically active as well as attentive to keep their bodies in a robust condition. Therefore, the protective effect of glucosamine in mortality might be overestimated.

Besides, glucosamine is also used for treatments in patients with the history of osteoarthritis who may have relatively poor prognoses. ${ }^{1}$ Therefore, the protective effect of glucosamine in mortality might be underestimated. These choices cause doubts of confounding by indication that tends to happen when the clinical indication for selecting a particular medicine is also linked to the outcome of interest. ${ }^{6}$

As mentioned above, the bias of (1) confounded doseresponse effect, (2) residual confounders and (3) confounding by indication should be taken into consideration to make this study more convincing based on the adequate database.

Hann-Ziong Yueh $\odot,{ }^{1}$ Chih-Jung Yeh, ${ }^{2}$ James Cheng-Chung Wei $\odot^{3,4,5}$

${ }^{1}$ Department of Medical Education, Chung Shan Medical University Hospital, Taichung, Taiwan

${ }^{2}$ Department of Public Health, Chung Shan Medical University, Taichung, Taiwan

${ }^{3}$ Institute of Medicine, Chung Shan Medical University, Taichung, Taiwan

${ }^{4}$ Department of Allergy, Immunology \& Rheumatology, Chung Shan Medical University Hospital, Taichung, Taiwan

${ }^{5}$ Graduate Institute of Integrated Medicine, China Medical University, Taichung, Taiwan

Correspondence to Dr James Cheng-Chung Wei, Institute of Medicine, Chung Shan Medical University, Taichung 40201, Taiwan; jccwei@gmail.com

Contributors $\mathrm{H}-\mathrm{ZY}$ and JCCW conceived and wrote the manuscript. C-JY reviewed and commented on the manuscript. All authors approved the final version of the manuscript.

Funding The authors have not declared a specific grant for this research from any funding agency in the public, commercial or not-for-profit sectors.

Competing interests None declared.

Patient and public involvement Patients and/or the public were not involved in the design, or conduct, or reporting, or dissemination plans of this research.

Patient consent for publication Not required.

Provenance and peer review Not commissioned; internally peer reviewed.

(c) Author(s) (or their employer(s)) 2020. No commercial re-use. See rights and permissions. Published by BMJ.

$$
\text { A Check for updates }
$$

To cite Yueh H-Z, Yeh C-J, Wei JC-C. Ann Rheum Dis Epub ahead of print: [please include Day Month Year]. doi:10.1136/annrheumdis-2020-218486

Received 3 July 2020

Accepted 7 July 2020

\section{S Linked}

http://dx.doi.org/10.1136/annrheumdis-2020-218659

Ann Rheum Dis 2020;0:1. doi:10.1136/annrheumdis-2020-218486

\section{ORCID iDs}

Hann-Ziong Yueh http://orcid.org/0000-0002-6776-0982

James Cheng-Chung Wei http://orcid.org/0000-0003-0310-2769

\section{REFERENCES}

1 Li Z-H, Gao X, Chung VC, et al. Associations of regular glucosamine use with allcause and cause-specific mortality: a large prospective cohort study. Ann Rheum Dis 2020;79:829-36.

2 Simon TG, Duberg A-S, Aleman S, et al. Association of aspirin with hepatocellular carcinoma and liver-related mortality. N Eng/ J Med 2020;382:1018-28.

3 Lousdal ML, Lash TL, Flanders WD, et al. Negative controls to detect uncontrolled confounding in observational studies of mammographic screening comparing participants and non-participants. Int J Epidemio/ 2020. doi:10.1093/ije/dyaa029. [Epub ahead of print: 25 Mar 2020].

4 Lipsitch M, Tchetgen Tchetgen E, Cohen T. Negative controls: a tool for detecting confounding and bias in observational studies. Epidemiology 2010;21:383-8.

5 Hamer M, Bauman A, Bell JA, et al. Examining associations between physical activity and cardiovascular mortality using negative control outcomes. Int J Epidemiol 2019;48:1161-6.

6 Kyriacou DN, Lewis RJ. Confounding by indication in clinical research. JAMA 2016;316:1818-9. 